\title{
Continuous infusion of amphotericin B: preliminary experience at Faculdade de Medicina da Fundação ABC
}

\author{
Faculdade de Medicina da Fundação ABC and Hospital Estadual Mário \\ Covas, Santo André, São Paulo, Brazil
}

INTREDUCTION

Invasive fungal infections have become a challenging issue with regard to neutropenic patients. Because of delays in diagnosing such infections, they are frequently fatal. Sometimes they are only diagnosed at the autopsy. ${ }^{1}$ Prolonged neutropenia is a major risk factor for invasive fungal infection. The incidence of invasive fungal infections ranges from $2 \%$ to $47 \%$, depending on many other concomitant risk factors (e.g. the use of steroids or lymphoid malignancies). ${ }^{2}$

In the early 1980s, many trials drew attention to the empirical and prophylactic application of antifungal drugs within such a scenario. In fact, amphotericin B deoxycholate (AmB-D) in the setting of persistent fever in neutropenic patients reduces the relative risk for documented invasive fungal infections by $50 \%$ to $80 \%$ and the overall mortality rate by $23 \%$ to $45 \% .^{2}$ The use of AmB-D in these patients is, however, limited by the frequent induction of nephrotoxicity and by the undesirable infusion-related side effects such as fever, rigors and chills. Because of this adverse toxicity profile, AmB-D has been compared unfavorably with new amphotericin formulations and other antifungal drugs. ${ }^{2}$

In the late 1990s, liposomal amphoteri$\operatorname{cin} \mathrm{B}(\mathrm{L}-\mathrm{AmB})$ emerged as a new option for the treatment for persistent fever in neutropenic patients by reducing the frequency of proven breakthrough fungal infections, with lower infusion-related toxic reactions and also reduced nephrotoxicity, ${ }^{2-4}$ in comparison with AmB-D. Recently, other antifungal drugs, such as new triazoles and caspofungin, have emerged as promising agents for the prevention of invasive fungal infections in persistently febrile neutropenic patients. ${ }^{2-4}$ In fact, in a comparative trial, voriconazole, a second-generation triazole, proved to be a suitable alternative to amphotericin B prepa- rations. ${ }^{4}$ The major inconvenience of these new antifungal drugs, however, is their higher cost, which may seriously hamper their use in underdeveloped countries.

Recently, a small randomized trial comparing continuous intravenous versus four-hour infusion of AmB-D showed a lower incidence of infusion related events and nephrotoxicity among the patients who received continuous intravenous infusion. ${ }^{5}$ Following the publication of these results, we also started to use AmB-D in the form of continuous 24-hour infusion. Here, we report on our preliminary experience with continuous infusion of AmB-D at our center, in terms of its efficacy and toxicity.

口BJECTIVE

To evaluate the efficacy, safety and toxicity of continuous infusion of AmB-D in febrile patients with neutropenia consequent to undergoing chemotherapy for hematological malignancies.

PATIENTS AND METHODS

This observational study was conducted in Faculdade de Medicina da Fundação ABC and Hospital Estadual Mário Covas in Santo André, which is a public, teaching healthcare institution, between October 2003 and May 2004.

Two of the initial 15 patients were excluded from the analyses. Two of these had another antifungal agent administered together with the continuous infusion of AmB-D, and the other had not received previous systemic chemotherapy. One patient received two cycles of continuous infusion of AmB-D and was analyzed twice, as each admission was considered as a separate event. A total of 13 procedures of continuous infusion of AmB-D were therefore administered.

The records of all 12 patients were retrospectively reviewed. The presence of toxicity and absence of breakthrough infection was
- Roberto Palermo Uehara

- Victor Hugo Lara de Sá

- Érika Tae Koshimura

- Fernanda Vilas Boas Prudente

- Luciana Tomanik Cardozo de Mello Tucunduva

- Marina Sahade Gonçalves

- Eliana Sueco Tibana Samano

- Auro del Giglio

\section{ABSTRACT}

CONTEXT AND OBJECTIVE: Intravenous amphotericin $B$ deoxycholate (AmB-D) infusions, usually given over 4 hours, frequently induce nephrotoxicity and undesirable infusion-related side effects such as rigors and chills. There is evidence in the literature that the use of AmB-D in the form of continuous 24-hour infusion is less toxic than the usual four-hour infusion of this drug. Our objective was to evaluate the efficacy and safety of continuous infusion of AmB-D for the treatment of persistent fever in neutropenic patients with hematological malignancies after chemotherapy

DESIGN AND SETIING: Observational retrospective analysis of our experience with continuous infusion of AmB-D, at Faculdade de Medicina da Fundação $A B C$ and Hospital Estadual Mário Covas in Santo André.

METHODS: From October 2003 to May 2004 12 patients with hematological malignancies and chemotherapy-induced neutropenia received 13 cycles of continuous infusion of AmB-D.

RESULTS: The median dose of AmB-D was 0.84 $\mathrm{mg} / \mathrm{kg} /$ day $(0.33$ to $2.30 \mathrm{mg} / \mathrm{kg} /$ day). Concomitant use of nephrotoxic medications occurred in $92 \%$ of the cycles. Nephrotoxicity occurred in $30.76 \%$ of the cycles, hypokalemia in $16.67 \%$, hepatotoxicity in $30 \%$ and adverse infusion-related events in $23 \%$. All patients survived for at least seven days after starting continuous infusion of AmB-D, and clinical resolution occurred in $76 \%$ of the cycles.

CONCLUSIONS: Continuous infusion of AmB-D can be used in our Institution as an alternative to the more toxic four-hour infusion of AmB-D and possibly also as an alternative to the more expensive liposomal formulations of the drug.

KEY WORDS: Amphotericin B. Neutropenia. Fever. Hematology. Leukemia. 
verified according to the following criteria proposed by Walsh: ${ }^{4}$

- Age between 15 and 70 years;

- Indication for receiving intravenous amphotericin B;

- Myelosuppressive systemic chemotherapy was previously administered;

- Persistent febrile neutropenia (absolute neutrophil count (ANC) of less than $1000 / \mathrm{mm}^{3}$ and temperature $\geq 37.8^{\circ} \mathrm{C}$ );

- At least five days of prior use of empirical broad-spectrum antibiotics;

- Normal renal function before intravenous $\mathrm{AmB}$ was started;

- Alanine aminotransferase and aspartate aminotransferase levels of no more than three times baseline;

- Bilirubin level of no more than three times baseline;

- No other antifungal agents, except for previous prophylaxis (which had to be discontinued prior to starting the continuous infusion of AmB-D).

Table 1. Demographic characteristics of patients undergoing chemotherapy for hematological malignancies

\begin{tabular}{|c|c|}
\hline $\begin{array}{l}\text { Characteristics of the patients } \\
\text { evaluated }\end{array}$ & Results \\
\hline Mean age $(n=13)$ & $\begin{array}{l}36.23 \\
\text { years }\end{array}$ \\
\hline \multicolumn{2}{|l|}{$\operatorname{Sex}(n=13)$} \\
\hline - Male & $23.1 \%$ \\
\hline - Female & $76.9 \%$ \\
\hline \multicolumn{2}{|l|}{ Race $(n=8)$} \\
\hline - White & $37.5 \%$ \\
\hline - Black & $50 \%$ \\
\hline - Other & $12.5 \%$ \\
\hline \multicolumn{2}{|l|}{ Diagnosis $(n=13)$} \\
\hline - Acute myelogenous leukemia & $61.5 \%$ \\
\hline - Non-Hodgkin's lymphoma (NHL) & $23.1 \%$ \\
\hline - Acute lymphocytic leukemia/NHL & $15.4 \%$ \\
\hline \multicolumn{2}{|l|}{ Site of infection $(n=13)$} \\
\hline - Indeterminate & $61.5 \%$ \\
\hline - Tonsils & $7.7 \%$ \\
\hline - Skin & $7.7 \%$ \\
\hline - Lung & $7.7 \%$ \\
\hline - Blood stream & $15.4 \%$ \\
\hline \multicolumn{2}{|l|}{ Fungal diagnosis criteria ${ }^{4}(n=13)$} \\
\hline $\begin{array}{l}\text { - Positive by bronchoalveolar } \\
\text { lavage }\end{array}$ & $15.4 \%$ \\
\hline $\begin{array}{l}\text { - Suggestive by radiologically } \\
\text { typical lesions findings }\end{array}$ & $53.8 \%$ \\
\hline $\begin{array}{l}\text { - Fungemia by positive } \\
\text { blood culture }\end{array}$ & $7.7 \%$ \\
\hline - Possible & $23.1 \%$ \\
\hline
\end{tabular}

Three of the initial 15 patients were excluded from the analyses. Two of these had another antifungal agent administered together with the continuous infusion of AmB-D, and the other had not received previous systemic chemotherapy. One patient received two cycles of continuous infusion of AmB-D and was analyzed twice as each admission was considered as a separate event. A total of 13 procedures of continuous infusion of AmB-D were therefore administered.

The records of all 12 patients were retrospectively reviewed. The presence of toxicity and absence of breakthrough infection was verified according to the following criteria proposed by Walsh: ${ }^{4}$

- Creatinine level increased to 1.5 times baseline value;

- Hypokalemia $\leq 2.5 \mathrm{mmol} / \mathrm{l}$;

- Hypomagnesemia $\leq 0.6 \mathrm{mmol} / \mathrm{l}$;

- Increased bilirubin levels;

- Aspartate aminotransferase (AST) or alanine aminotransferase (ALT) level of more than five times baseline values, if these values were greater than the reference range. Hepatotoxicity was also deemed to be present when AST or ALT was three times more than baseline, if the baseline was between two and five times the normal range. On the other hand, if the baseline was between 5 and 10 times the normal range, AST or ALT only had to reach twice the baseline value for hepatotoxicity to be deemed present. The baseline values were considered to be the laboratory values obtained immediately before the continuous infusion of AmB-D was started.

Because of drug stability concerns, the total dose of AmB-D required ( $\mathrm{mg} / \mathrm{kg} /$ day) was divided into four doses, and each of these was given as a 6-hour infusion procedure. Each quarter of the total dose was thus given in the form of $250 \mathrm{ml}$ of $5 \%$ glucose solution, without any additives.

The infusion-related toxic reactions were retrospectively estimated from the frequency with which our Institution's protocol for the treatment of fever, chills and rigors secondary to AmB-D infusion was utilized (i.e. considering any use of acetaminophen, diphenhydramine, steroids or meperidine during the period of continuous infusion of AmB-D). Concomitant use of other nephrotoxic drugs was defined as the simultaneous use of aminoglycoside, foscarnet or cyclosporin.

The degree of certainty of the diagnosis of fungal infection was defined according to the Walsh criteria: ${ }^{4}$
- Proven: by biopsy or bronchoalveolar lavage;

- Probable: by radiologically typical lesions;

- Fungemia: positive blood culture;

- Possible: none of the above.

The primary efficacy of the treatment was defined as a composite of the following criteria, as proposed by Walsh: ${ }^{4}$

- Survival for 7 days after starting to use the study drug;

- Resolution of fever during the period of neutropenia;

- Successful treatment of any baseline fungal infection, if present;

- Absence of breakthrough fungal infection during administration of the study drug or within seven days after the completion of treatment;

- Absence of premature discontinuation of the drug because of toxicity or lack of efficacy.

RESULTS

Among the patients included, $76.9 \%$ were female, the mean age was 36.23 years and $61.5 \%$ had acute myelogenous leukemia as the diagnosis (Table 1).

In $61.5 \%$ of the cases, the site of fungal infection could not be determined. In $53.8 \%$, the presumptive diagnosis was based on radiographic findings, while bronchoalveolar lavage/sputum was positive in $15.4 \%$, and positive blood culture occurred in only $7.7 \%$ of the cases (Table 1).

The mean length of time since the previous broad-spectrum antibacterial therapy was 18.23 days, and a mean of 3.84 antibiotics had previously been administered to each patient. Prophylactic fluconazole had been prescribed for $61.5 \%$ of the patients. The mean rate for the continuous infusion of AmB-D was $0.84 \mathrm{mg} / \mathrm{kg} /$ day (range from 0.33 to $2.30 \mathrm{mg} / \mathrm{kg} /$ day).

In $30.76 \%$ of the patients, the creatinine level increased to 1.5 times baseline, but $92.4 \%$ of them were also taking other nephrotoxic drugs (aminoglycoside in all cases). Adverse infusion-related events were present in $23 \%$ of the cycles and hepatotoxicity in $30 \%$ of them (Table 2 ).

With regard to the efficacy criteria, $100 \%$ of the patients were alive one week after continuous infusion of AmB-D started. Three fungal infections were documented, and two of these $(66.60 \%)$ resolved completely. Breakthrough fungal infection was absent in $92.30 \%$ of the cases. There was no discontinuation of the drug due to toxicity or absence of 
efficacy, nor was there any need for association with another antifungal agent. In $76.92 \%$ of the cases, the fever resolved while the patient was still in the neutropenic period (Table 3).

\section{DISCUSSIRN}

Fungal infections within a scenario of neutropenia are always a challenge in caring for cancer patients, especially after chemotherapy. Because of the potential for high morbidity and mortality, any delay in diagnosing such infections may be fatal. Invasive fungal infection rates have ranged from $3 \%$ to $42 \%$ in patients with acute myelogenous leukemia treated with cytarabine and anthracyclinebased chemotherapeutic regimens, and the mortality rates may reach $6 \%$ to $60 \%$. $^{6}$

During the last twenty years many different drugs have been developed to ameliorate and control fungal infections. On the other hand, economic issues related to this new formulations have been voiced. In the 1990 s, L-AmB emerged as an alternative for the treatment of febrile neutropenic patients and was shown to be as effective as AmB-D and to cause lower infusion-related toxicity, less nephrotoxicity and fewer breakthrough fungal infections. ${ }^{3}$ Recently, a randomized trial was reported in which, despite the high cost of L-AmB, the pharmacoeconomic issues favored the use of $\mathrm{L}-\mathrm{AmB}$ for patients at a high risk of developing renal failure. It was also suggested that to change patients from AmB-D to L-AmB after high levels of toxicity have developed may not be the most cost-effective strategy.

Amphotericin B formulations have been compared in a systematic review, in which it was shown that L-AmB significantly reduced the risk of all causes of mortality by an estimated 28\%, compared with conventional AmB-D (odds ratio, $\mathrm{OR}=0.72$; confidence interval, CI: 0.54 to 0.97$)$. There was no significant difference in efficacy between L-AmB and $\mathrm{AmB}-\mathrm{D}(\mathrm{OR}=1.21$; $\mathrm{CI}: 0.98$ to 1.49$)$. Amphotericin B lipid complex and L-AmB were found to significantly reduce the risk of doubling the serum creatinine level, by an estimated $58 \%(\mathrm{OR}=0.42$; CI 0.33 to 0.54$)$. Comparing the lipid-based formulations with conventional AmB-D, the overall number of patients needed to treat (NNT) in order to prevent one death was 31 . The NNT in order to prevent the doubling of the serum creatinine level for both amphotericin B lipid complex and L-AmB, in comparison with AmB-D, was six patients. ${ }^{8}$

Although some studies have supported the use of L-AmB as a standard antifungal agent, on the basis of its efficacy and from cost effectiveness analyses, many institutions have to limit their routine use of this practice because of the very high cost of L-AmB. Interestingly, in a recent randomized controlled trial that compared the use of 4 or 24-hour infusion of AmB-D, the 24-hour infusion of AmB-D reduced nephrotoxicity and the side effects related to infusion, without increased mortality. ${ }^{5}$ Continuous infusion of AmB-D therefore emerges as an interesting investigational alternative in the recent literature because of its promisingly low toxicity profile, effective antifungal activity and significantly lower cost. In fact, one milligram of $\mathrm{L}-\mathrm{AmB}$ is about 35 times more expensive than one milligram of AmB-D (data not presented).

In our observational study, continuous infusion of AmB-D produced nephrotoxicity in $30.75 \%$ of the cycles, which was similar to the rate reported by Eriksson 5 (33\%) with 24 hour infusion of AmB-D and Walsh (29.40\%) with L-AmB. ${ }^{3}$

These results represent a marked reduction in comparison with classic AmB-D therapy (Table 2). Hypokalemia seemed to be higher in our study, maybe due to the higher rate of concomitant use of other nephrotoxic drugs. Therefore, we strongly recommend potassium and magnesium supplementation, even after completing the therapy of continuous infusion of AmB-D. Hepatotoxicity was also a concern. Interestingly, one of the two patients who had the most marked increase in

Table 2. Comparison of efficacy, safety and infusion-related toxic effect of amphotericin B in patients with hematological malignancies

\begin{tabular}{|c|c|c|c|c|}
\hline & $\begin{array}{l}\text { Continuous infusion of } \\
\text { amphotericin B } \\
\text { deoxycholate } \\
\text { (present study) }\end{array}$ & $\begin{array}{c}\text { Continuous infusion of am- } \\
\text { photericin B } \\
\text { deoxycholate } \\
\left.\text { (Eriksson et al. }{ }^{5}\right)\end{array}$ & $\begin{array}{l}\text { Amphotericin B } \\
\text { deoxycholate } \\
\text { (Walsh et al. }{ }^{3} \text { ) }\end{array}$ & $\begin{array}{c}\text { Liposomal } \\
\text { amphotericin B } \\
\text { (Walsh et al. }{ }^{3} \text { ) }\end{array}$ \\
\hline Creatinine $>1.5 \times$ baseline & $30.76 \%$ & $33 \%$ & $49.40 \%$ & $29.40 \%$ \\
\hline $\begin{array}{l}\text { Other concomitant } \\
\text { nephrotoxic drugs }\end{array}$ & $92.40 \%$ & $28 \%$ & $15.20 \%$ & $6.30 \%$ \\
\hline Hypokalemia $(\leq 2.5)$ & $16.67 \%$ & $10 \%$ & $11.60 \%$ & $6.70 \%$ \\
\hline Hepatotoxicity & $30 \%$ & - & $20.30 \%$ & $17.80 \%$ \\
\hline Infusion-related effects (chills) & $23.07 \%$ & $13 \%$ & $73.5 \%$ & $37.6 \%$ \\
\hline
\end{tabular}

Table 3. Comparative primary efficacy endpoints of amphotericin formulations in neutropenic patients

\begin{tabular}{|c|c|c|c|}
\hline Efficacy end point & $\begin{array}{l}\text { Continuous infusion of } \\
\text { amphotericin B } \\
\text { deoxycholate }\end{array}$ & $\begin{array}{l}\text { Amphotericin B } \\
\text { deoxycholate } \\
\text { (Walsh et al. }{ }^{3} \text { ) }\end{array}$ & $\begin{array}{c}\text { Liposomal } \\
\text { amphotericin B } \\
\text { (Walsh et al. }{ }^{3} \text { ) }\end{array}$ \\
\hline 1- Seven-day survival following infusion of amphotericin B deoxycholate & $100 \%$ & $89.50 \%$ & $92.70 \%$ \\
\hline 2- Successful treatment of baseline fungal infection & $66.60 \%$ & $72.70 \%$ & $81.80 \%$ \\
\hline 3- Absence of breakthrough infection during the study period & $92.30 \%$ & $89.20 \%$ & $90.10 \%$ \\
\hline 4- Absence of premature discontinuation due to loss of efficacy or high toxicity & $0 \%$ & $18.60 \%$ & $14.3 \%$ \\
\hline 5- Resolution of fever during neutropenia & $76.92 \%$ & $58.10 \%$ & $58 \%$ \\
\hline
\end{tabular}


the liver function tests had also had a course of fluconazole treatment lasting 59 days, prior to the continuous infusion of AmB-D.

The continuous infusion of AmB-D used in our study was effective. In fact, in this small observational study, there were no deaths during the first seven days after starting the continuous infusion of AmB-D, there was no discontinuation due to lack of efficacy or extreme toxicity, and no other concomitant an- tifungal drugs were necessary. Table 3 presents a comparison between our data and results in the literature for AmB-D and L-AmB.

Although this was a retrospective study with a small number of patients, the results are interesting and very encouraging for us to start planning a prospective trial of continuous infusion of AmB-D in neutropenic patients with dose escalation allied to pharmacoeconomic considerations.
CDNCLUSIRN

Continuous infusion of AmB-D in our small retrospective experience was safe, cheap and effective. Further improvement in the outcomes from treating patients using continuous infusion of AmB-D may be possible with dose escalation. Prospective studies are needed in order to further explore the favorable pharmacoeconomic profile of this drug, and to reproduce our preliminary experience with this drug.

\section{REFERENCES}

1. Bodey G, Bueltmann B, Duguid W, et al. Fungal infections in cancer patients: an international autopsy survey. Eur J Clin Microbiol Infect Dis. 1992;11(2):99-109.

2. Donowitz GR, Maki DG, Crnich CJ, Pappas PG, Rolston $\mathrm{KV}$. Infections in the neutropenic patient - new views of an old problem. Hematology (Am Soc Hematol Educ Program). 2001:113-39.

3. Walsh TJ, Finberg RW, Arndt C, et al. Liposomal amphotericin B for empirical therapy in patients with persistent fever and neutropenia. National Institute of Allergy and Infectious Diseases Mycoses Study Group. N Engl J Med. 1999;340(10):764-71

\section{AUTHOR INFDRMATIDN}

Roberto Palermo Uehara, MD. Assistant professor, Faculdade de Medicina do ABC, Hospital Estadual Mário Covas, Santo André, São Paulo, Brazil.

Victor Hugo Lara de Sá. Medical student, Faculdade de Medicina do ABC, Hospital Estadual Mário Covas, Santo André, São Paulo, Brazil.

Érika Tae Koshimura. Medical student, Faculdade de Medicina do $A B C$, Hospital Estadual Mário Covas, Santo André, São Paulo, Brazil

Fernanda Vilas Boas Prudente. Medical student, Faculdade de Medicina do ABC, Hospital Estadual Mário Covas, Santo André, São Paulo, Brazil.

Luciana Tomanick Cardozo de Mello Tucunduva. Medical student, Faculdade de Medicina do ABC, Hospita Estadual Mário Covas, Santo André, São Paulo, Brazil.

Marina Sahade Gonçalves. Faculdade de Medicina do $A B C$, Hospital Estadual Mário Covas, Santo André, São Paulo, Brazil.

Eliana Sueco Tibana Samano. Medical student, Faculdade de Medicina do ABC, Hospital Estadual Mário Covas, Santo André, São Paulo, Brazil.

Auro del Giglio, MD, FACP. Chairman of Oncology and Hematology, Faculdade de Medicina do ABC, Hospital Estadual Mário Covas, Santo André, São Paulo, Brazil.

Address for correspondence:

Auro del Giglio

Av. Rebouças, 3.387 - Pinheiros.

São Paulo (SP) - Brasil - CEP 05401-450

Tel./Fax. (+55 11) 3819-5007

E-mail: sandrabr@netpoint.com.br
4. Walsh TJ, Pappas P, Winston DJ, et al. Voriconazole compared with liposomal amphotericin B for empirical antifungal therapy in patients with neutropenia and persistent fever. $\mathrm{N}$ Engl J Med. 2002;346(4):225-34.

5. Eriksson U, Seifert B, Schaffner A. Comparison of effects of amphotericin B deoxycholate infused over 4 or 24 hours: randomised controlled trial. BMJ. 2001;322(7286):579-82.

6. Rotstein C, Bow EJ, Laverdiere M, Ioannou S, Carr D, Moghaddam N. Randomized placebo-controlled trial of fluconazole prophylaxis for neutropenic cancer patients: benefit based on purpose and intensity of cytotoxic therapy. The Canadian Fluconazole Prophylaxis Study Group. Clin Infect Dis. 1999;28(2):331-40.
7. Cagnoni PJ, Walsh TJ, Prendergast MM, et al. Pharmacoeconomic analysis of liposomal amphotericin $B$ versus conventional amphotericin B in the empirical treatment of persistently febrile neutropenic patients. J Clin Oncol. 2000;18(12):2476-83.

8. Barrett JP, Vardulaki KA, Conlon C, et al. A systematic review of the antifungal effectiveness and tolerability of amphotericin B formulations. Clin Ther. 2003;25(5):1295-320.

Sources of funding: None

Conflict of interest: None

Date of first submission: 26/8/2004

Last received: 10/8/2005

Accepted: 10/8/2005

RESUMD

Uso de anfotericina B infusional: uma experiência preliminar da Faculdade de Medicina da fundação $A B C$

CONTEXTO E OBJETIVO: Pacientes neutropênicos com febre persistente podem apresentar infecções fúngicas com freqüência. A administração de anfotericina $B$ deoxicolato tem sido padrão para estes pacientes, no entanto sua infusão endovenosa, usualmente administrada em quatro horas, pode levar a nefrotoxicidade, hepatotoxicidade e efeitos adversos relacionados à infusão, como tremores e calafrios. A literatura evidencia que o uso de anfotericina B deoxicolato em infusão contínua de 24 horas pode ser menos tóxica em relação à administração usual. $\bigcirc$ objetivo do estudo foi avaliar a eficácia, segurança e toxicidade da anfotericina $B$ infusional contínua em pacientes onco-hematológicos após quimioterapia com neutropenia febril persistente.

TIPO DE ESTUDO E LOCAL: Estudo observacional e retrospectivo de nossa experiência com anfotericina $B$ deoxicolato em infusão contínua de 24 horas, na Faculdade de Medicina da Fundação ABC e Hospital Estadual Mário Covas, em Santo André.

MÉTODOS: No período entre outubro de 2003 e maio de 2004, 12 pacientes com neoplasias hematológicas e neutropenia febril induzida por quimioterapia receberam 13 ciclos de anfotericina $B$ deoxicolato infusional.

RESULTADOS: A dose média da infusão foi de $0,84 \mathrm{mg} / \mathrm{kg} /$ dia. $\bigcirc$ uso concomitante de outras drogas nefrotóxicas ocorreu em $92 \%$ dos ciclos. Foram observados nefrotoxicidade em 30,76\%, hipocalemia em $16,67 \%$, hepatotoxicidade em $30 \%$ e efeitos adversos relacionados à infusão em $23 \%$ dos ciclos. Todos os pacientes sobreviveram aos sete primeiros dias após o início do tratamento e a resolução clínica ocorrev em $76 \%$ dos ciclos.

CONCLUSÃO: A infusão contínua de anfotericina B é exeqüível para uso em nossa instituição como alternativa à infusão em quatro horas (mais tóxica) e possivelmente às caras formulações lípidicas desta droga.

PALAVRAS-CHAVE: Anfotericina B. Neutropenia. Febre. Hematologia. Leucemia. 